$1^{\text {st }}$ International Multidisciplinary Conference on Nutraceuticals and Functional Foods

Current Research in Nutrition and Food Science

Vol. 4(SI. 2), 48-53 (2016)

\title{
Probiotic Yogurt Production with Lactobacillus casei and Prebiotics
}

\section{EVAGELIA MARINAKI ${ }^{1}$, PANAGIOTIS KANDYLIS ${ }^{1 *}$, DIMITRA DIMITRELLOU1, GEORGIOS ZAKYNTHINOS ${ }^{1}$ and THEODOROS VARZAKAS ${ }^{1,2}$}

\author{
${ }^{1}$ Department of Food Technology, Technological and Educational Institution \\ of Peloponnese, Antikalamos, Kalamata 24100, Greece. \\ ${ }^{2}$ Ghent University Global Campus, Incheon, South Korea.
}

http://dx.doi.org/10.12944/CRNFSJ.4.Special-Issue-October.07

(Received: August, 2016; Accepted: September, 2016)

\begin{abstract}
In the present study the effect of the addition of prebiotic, raffinose, on the main physicochemical characteristics of yogurts after storage at $4^{\circ} \mathrm{C}$ for 4 weeks was studied. More specifically yogurts were produced using the probiotic microorganism Lactobacillus casei ATCC 393 in combination with the traditional yogurt culture Lactobacillus delbrueckii ssp. bulgaricus and Streptococcus thermophilus. Four different types of yogurts were produced with the addition of $0,0.5,1$ and $2 \% \mathrm{w} / \mathrm{v}$ raffinose. During storage of yogurts several physicochemical characteristics were monitored such as $\mathrm{pH}$, titratable acidity, syneresis and water holding capacity. No significant differences were observed in physicochemical characteristics with the addition of raffinose. The organoleptic evaluation of the produced yogurts revealed the superiority of yogurts with raffinose and especially those with $1 \% \mathrm{w} / \mathrm{v}$ raffinose in comparison with the yogurt without raffinose. The use of raffinose retained the viability of probiotic culture in high numbers even after 4 weeks of storage $\left(>10^{8} \mathrm{cfu}^{-1}\right)$, which is higher than those without raffinose.
\end{abstract}

Keywords: raffinose, fermented milk, yogurt, L. casei, probiotic, prebiotic.

\section{INTRODUCTION}

The development of novel functional foods containing probiotic is a highly growing area of the food industry and attracts special interest from the field of nutrition, due to their beneficial properties to human health ${ }^{1}$. However, to deliver their health benefits, probiotics must be present in food products above a threshold level ( $>6 \operatorname{log~cfu~g}^{-1}$ ) at the time of consumption, in order to survive the passage through the upper and lower parts of the gastrointestinal (GI) tract $^{2}$. Lactobacillus casei ATCC 393 strain has been reported to have beneficial effects for cholesterol removal $^{3}$, reduction of the risk of osteoporosis ${ }^{4}$, activity against cancer cell proliferation ${ }^{5}$, beneficial tumor-inhibitory, anti-proliferative and pro-apoptotic effects ${ }^{6}$, survived the passage through the GI tract in a rat model and potential regulates intestinal microbiota 7 . In addition L. casei ATCC 393 is a strain with satisfying technological characteristics and therefore has numerous applications in the production of food products such as cheese ${ }^{8}$, sausages $^{9}$, fermented milks $s^{4,7,10}$ and yogurts ${ }^{11,12}$.

Prebiotics are short-chain carbohydrates, which are non-digestible by humans ${ }^{13}$ and selectively stimulate the growth and/or activity of one or a limited number of bacteria ${ }^{14}$. More specifically they pass by the small intestine to the lower gut where they utilized by probiotic bacteria but not by other intestinal bacteria ${ }^{15}$. Most of the studies on prebiotics concern fructooligosaccharides (with plant origin such as chicory roots, garlic, onion etc), galactooligosaccharides (with origin through enzymatic conversion lactose) and inulin ${ }^{16}$. However considerable attention has been given 
in the so called raffinose family oligosaccharides RFOs ( $\alpha$-galactosides), having their origin from seeds of legumes, lentils, peas, beans, chickpeas, mallow composite, and mustard and represented by raffinose, stachyose, verbascose and other oligosaccharides ${ }^{15}$. RFOs and especially raffinose and stachyose positively affected probiotic increase (Bifidobacteria and Lactobacillus), Fe bioavailability and brush border membrane functionality in vivo ${ }^{17}$. In addition RFOs have been incorporated in fermented milks and provided a beneficial effect in L. acidophilus $^{18}$, Bifidobacterium lactis $\mathrm{Bb}-12^{19}$ and a combined culture of them $(1: 1)^{20}$. Raffinose in a synthetic medium was tested as prebiotic in several lactobacilli (among them L. casel) and in its presence the growth of Lactobacilli was statistically improved ${ }^{16}$. In a preclinical study, where the effects of raffinose and Bifidobacterium breve JCM 1192T administration was studied, the results showed that raffinose influences on the cecal proliferation of Bifidobacterium breve JCM $1192 \mathrm{~T}^{21}$. These results support the concept of combining a probiotic strain with its preferred prebiotic substrate. Therefore the aim of the present study was to evaluate the use of raffinose as prebiotic in the production of probiotic yogurt using traditional yogurt starters and probiotic L. casei ATCC 393 cells.

\section{MATERIALS AND METHODS}

\section{Strains}

Lactobacillus casei ATCC 393 (DSMZ, Braunschweig, Germany) was used as probiotic strain. The thermophilic starter, $\mathrm{CH}-1$ (Chr. Hansen, Hørsholm, Denmark) consisted of Streptococcus thermophilus and Lactobacillus delbrueckii spp. bulgaricus in a freeze-dried form was also employed in the present study. All cultures were prepared, as described in previous study ${ }^{10}$.

\section{Yogurt manufacture}

Pasteurized bovine milk (3.7\% fat) was heated at $42{ }^{\circ} \mathrm{C}$ and raffinose was added in several amounts (up to $2.0 \% \mathrm{w} / \mathrm{v}$ ). Then L. casei ATCC 393 cells $\left(1 \mathrm{~g} \mathrm{~L}^{-1}\right)$ were added. After $15 \mathrm{~min}$, all samples were inoculated with the activated $\mathrm{CH}-1$ culture $(0.3 \% \mathrm{v} / \mathrm{v})$. The fermentation was terminated at $\mathrm{pH}$ 4.7 and the samples stored at $4^{\circ} \mathrm{C}$ for 28 days.

\section{Determination of culture viability}

Yogurt samples were added to $1 / 4$ Ringer's solution and the appropriate serial dilutions were prepared. L. casei was enumerated in lithium propionate MRS (LP-MRS) agar (lithium chloride $0.2 \% \mathrm{w} / \mathrm{v}$ and sodium propionate $0.3 \% \mathrm{w} / \mathrm{v}$ ) at $37^{\circ} \mathrm{C}^{22}$.

\section{Determination of $\mathrm{pH}$ and titratable acidity of yogurts}

$\mathrm{pH}$ of yogurts was measured using a $\mathrm{pH}-$ meter and titratable acidity was determined by titration using $0.1 \mathrm{~mol} \mathrm{~L}^{-1} \mathrm{NaOH}$ and phenolphthalein as an indicator and expressed as $\mathrm{g}$ of lactic acid per $100 \mathrm{~g}$ yogurt.

\section{Syneresis of yogurts}

$50 \mathrm{~mL}$ of unstirred yogurt spread evenly on a Whatman No. 1 filter paper in a funnel. After $5 \mathrm{~h}$ at $4^{\circ} \mathrm{C}$, the volume of liquid collected was recorded and multiplied with 2 giving \% syneresis.

\section{Sensory evaluation}

20 panelists familiar with the consumption of yogurts from the Department of Food Technology, were used to evaluate the produced yogurts for color, sweet odor, smoothness, sweetness, viscosity and overall acceptability, using a 9-point hedonic scale ranging from 1 ("dislike extremely") to 9 ("like extremely").

\section{Statistical analysis}

Significance was established at $\mathrm{P}<$ 0.05 . The results were analyzed for statistical significance by ANOVA, and Tukey honest significant. Coefficients, ANOVA tables, and significance ( $\mathrm{P}<$ $0.05)$ were computed using Statistica version 5.0 (StatSoft Inc., Tulsa, OK).

\section{RESULTS AND DISCUSSION}

L. casei ATCC 393 has been proposed for the production of several dairy products due to its excellent technological properties and the health benefits related to its consumption. However, there are some additional important requirements that have to be fulfilled by each probiotic in order to be suitable for food applications. The probiotic culture should be prepared in a dry state in order to comply 
with the commercial needs of industry and also should be capable to survive the harsh conditions of the $\mathrm{Gl}$ tract of humans ${ }^{23}$. These two requirements have been extensively studied and fulfilled by $L$. casei ATCC 393. More specifically L. casei ATCC 393 cells have been prepared in dried form either using freeze drying ${ }^{24}$ or spray drying ${ }^{10}$ with good survival rates. In addition their capability to survive the harsh conditions of the Gl tract has been proved by several studies either in free or microencapsulated form ${ }^{10,25}$. Therefore, in the present study, the use of prebiotics in combination with $L$. casei for yogurt production was studied in order to further increase the previous mentioned characteristics of $L$. casei cells. To the best of our knowledge, this is the first report concerning the production of yogurt using prebiotics such as raffinose with $L$. casei providing a complete research assay for ease industrial exploitation.

\section{Effect of prebiotics on $\mathrm{pH}$ and titratable acidity of yogurts}

The addition of raffinose did not affect the fermentation time for the production of probiotic yogurts (data not shown). The physicochemical characteristics of yogurts with or without raffinose during 28 days of storage are presented in Table 1. Titratable acidity was continuously increased during storage up to $1.09-1.18 \mathrm{~g} / 100 \mathrm{~g}$ of yogurt and was significantly $(P<0.05)$ affected by the storage time. In contrast, no significant differences were observed between products produced with and without raffinose. In the same way, the $\mathrm{pH}$ values of yogurts decreased rapidly during the first week of storage but after that remained constant to values 4.05-4.10.

\section{Effect of prebiotics on syneresis of yogurts}

Whey separation (wheying-off or syneresis) is defined as the expulsion of whey from the yogurt's protein matrix which then becomes visible as surface whey. This phenomenon adversely affects consumer perception of yogurt, as they consider that there is a microbiological problem ${ }^{26}$. Yogurt manufacturers, in order to reduce or eliminate this problem, usually use stabilizers such as starch, gelatin and vegetable gum or increase the level of milk solids and especially of the protein percentage ${ }^{27}$. Spontaneous syneresis, which is contraction of gel without the application of any external force, is the usual cause of whey separation and is related to an unstable network, which can be due to an increase in the rearrangements of the gel matrix or it can be induced by damage to the weak gel network (e.g., by vibration or cutting) $)^{28}$.

In the present study the use of raffinose as prebiotic did not affect the syneresis of the yogurts resulting to similar values of syneresis compare to yogurts without prebiotics (Table 1). More specifically the syneresis ranged from $33 \%$ to $40 \%$ during the 28 days of storage at $4{ }^{\circ} \mathrm{C}$. Only the use of high raffinose content $2 \%$ w/v led to significantly $(P<0.05)$ higher values of syneresis ranging from $37 \%$ to $43 \%$. These results are very important for the dairy industries

Table 1: Effect of storage and raffinose content on physicochemical characteristics of probiotic yogurts with $L$. casei

\begin{tabular}{lccccc}
\hline Analysis & $\begin{array}{c}\text { Storage } \\
\text { time (days) }\end{array}$ & $\mathbf{0}$ & Raffinose content (\% w/v of milk) \\
& 7 & $4.10 \pm 0.04$ & $4.08 \pm 0.03$ & $4.07 \pm 0.03$ & $\mathbf{1 . 0}$ \\
\hline $\mathrm{pH}$ & 14 & $4.09 \pm 0.03$ & $4.03 \pm 0.02$ & $4.07 \pm 0.04$ & $4.01 \pm 0.03$ \\
& 28 & $4.10 \pm 0.03$ & $4.07 \pm 0.02$ & $4.06 \pm 0.02$ & $4.08 \pm 0.02$ \\
& 7 & $0.97 \pm 0.01$ & $0.99 \pm 0.02$ & $0.99 \pm 0.03$ & $0.95 \pm 0.02$ \\
Acidity & 14 & $1.13 \pm 0.02$ & $1.09 \pm 0.02$ & $1.01 \pm 0.01$ & $1.04 \pm 0.02$ \\
(\% w/w lactic acid) & 28 & $1.12 \pm 0.02$ & $1.11 \pm 0.01$ & $1.18 \pm 0.02$ & $1.09 \pm 0.03$ \\
& 7 & $33.5 \pm 0.5$ & $38.5 \pm 0.8$ & $35.5 \pm 1.3$ & $43.0 \pm 1.6$ \\
Syneresis (\%) & 14 & $40.0 \pm 0.7$ & $40.0 \pm 0.9$ & $40.0 \pm 0.9$ & $42.5 \pm 1.0$ \\
& 28 & $36.0 \pm 0.6$ & $34.0 \pm 1.2$ & $40.0 \pm 1.5$ & $37.0 \pm 0.9$ \\
\hline
\end{tabular}




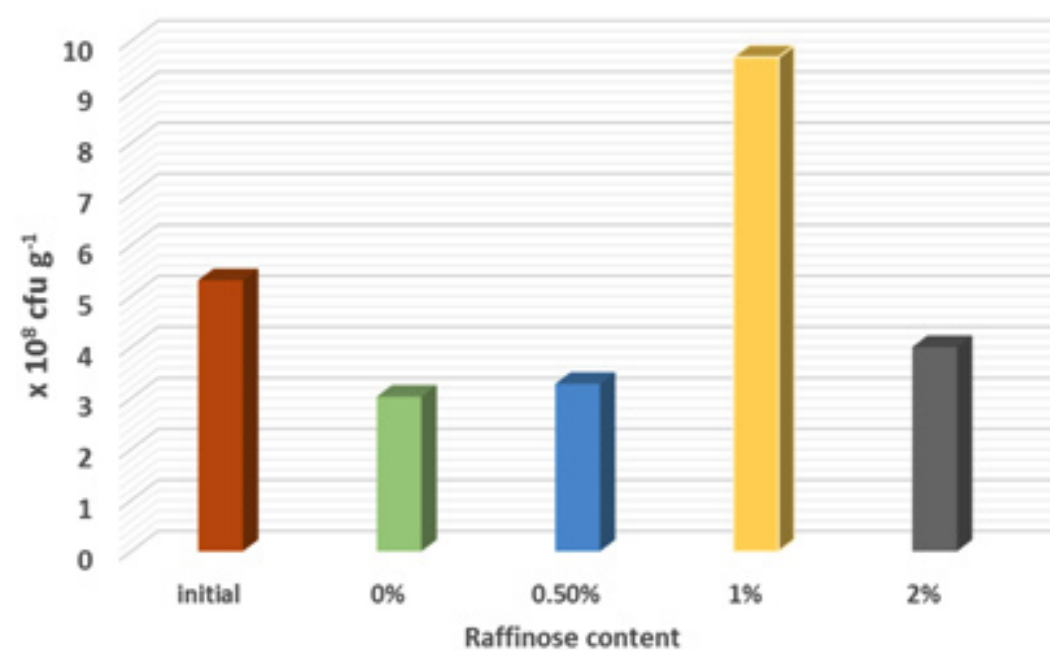

Fig. 1: Effect of storage ( 28 days at $4^{\circ} \mathrm{C}$ ) and raffinose content on viability of $L$. casei in probiotic yogurts

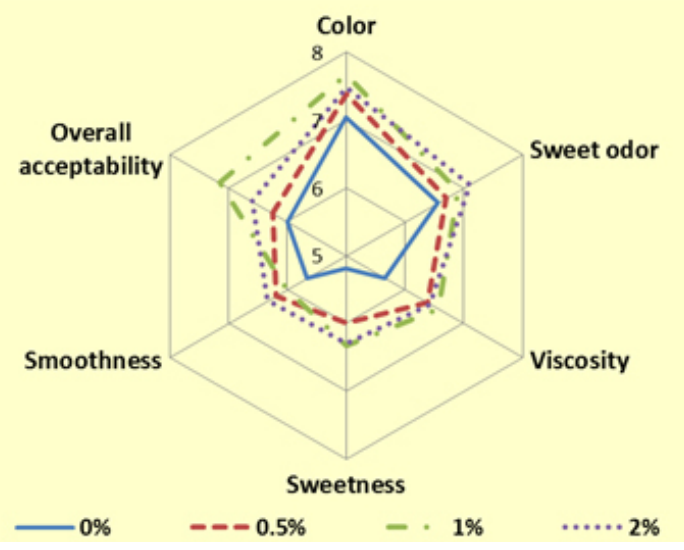

Fig. 2: Sensory evaluation of probiotic yogurts produced using different raffinose concentrations

since the addition of raffinose did not affect the textural characteristics of yogurts as proved by the syneresis values.

\section{Effect of prebiotics on survival of $L$. casei ATCC 393 cells}

The microbiological analysis of the produced yogurts (Figure 1) showed the viability of probiotic culture during storage. After yogurt production the viable cells of $L$. casei were $5.3 \times 10^{8} \mathrm{cfu} \mathrm{g}^{-1}$ of yogurt. After 28 days of storage at $4^{\circ} \mathrm{C}$, in all cases the viable numbers of $L$. casei remained in values higher than $10^{6} \mathrm{cfu} \mathrm{g}^{-1}$ that is necessary to confer the probiotic character of the products. In addition in all cases a significant $(P<0.05)$ decreased in viable $L$. casei cells was observed to values ranging between 3.0 $\times 10^{8}$ and $4.0 \times 10^{8} \mathrm{cfu} \mathrm{g}^{-1}$ of yogurt. However in the yogurt with $1 \% \mathrm{w} / \mathrm{v}$ raffinose a significant $(P<0.05)$ increase in the viable cells of $L$. casei was observed to $9.7 \times 10^{8} \mathrm{cfu} \mathrm{g}^{-1}$ of yogurt.

\section{Sensory evaluation of yogurts}

The results of sensory evaluation of the new products are presented in Figure 2. The results showed that, in most cases, no significant differences were observed between yogurts produced with the addition of raffinose. However, the samples with raffinose presented significantly $(P<0.05)$ higher values in all cases compared to the control sample (without raffinose). Sample with $1 \% \mathrm{w} / \mathrm{v}$ raffinose received significantly $(P<0.05)$ higher scores in overall acceptability compared to all other samples. These findings indicated the high industrial potential of the proposed technology since sensory evaluation showed the acceptance of the new yogurts from the panelists and no defect was mentioned by them.

\section{CONCLUSIONS}

In conclusion, the use of raffinose as prebiotic in yogurt production is very promising since no defects in the production of yogurts observed. Similarly, the proposed technology resulted in significantly higher cell counts during production and refrigerated storage of yogurts over 
products without raffinose. Noticeably, the probiotic levels ranged above the minimum requirement for conferring a probiotic effect, especially when $1 \% \mathrm{w} / \mathrm{v}$ raffinose was used, and the new products were of improved sensory characteristics, while the overall high quality was ascertained by the organoleptic tests. Since probiotic culture is important to survive the passage through the upper and lower parts of the Gl tract ${ }^{2}$, future studies will give more insight into the role of prebiotic to protect $L$. casei cells also under gastrointestinal conditions. Finally since there is evidence that prebiotics based on raffinose, RFOs, stimulate the growth of Lactobacilli and as a consequent suppress the growth of pathogens such as Escherichia coli and Salmonella enteric serovar Typhimurium $^{29}$, future studies may also focus on the evaluation of symbiotic effect of raffinose prebiotics and probiotic L. casei ATCC 393 cells on various pathogens in dairy products.

\section{REFERENCES}

1. Saxelin M. Probiotic formulations and applications, the current probiotics market, and changes in the marketplace: a European perspective. Clinical Infectious Diseases; 46(Supplement 2): S76-S79: (2008).

2. Boylston T. D, Vinderola C. G, Ghoddusi H. B, Reinheimer J. A. Incorporation of bifidobacteria into cheeses: challenges and rewards. International Dairy Journal; 14(5): 375-387: (2004).

3. Lye H. S, Rusul G, Liong M. T. Removal of cholesterol by lactobacilli via incorporation and conversion to coprostanol. Journal of Dairy Science; 93(4): 1383-1392: (2010).

4. Kim J. G, Lee E, Kim S. H, Whang K.Y, Oh S, Imm J.Y. Effects of a Lactobacillus casei 393 fermented milk product on bone metabolism in ovariectomised rats. International Dairy Journal; 19(11): 690-695: (2009).

5. Choi S. S, Kim Y, Han K. S, You S, Oh S, Kim S. H. Effects of Lactobacillus strains on cancer cell proliferation and oxidative stress in vitro. Letters in Applied Microbiology, 42(5): 452458: (2006).

6. Tiptiri-Kourpeti A, Spyridopoulou K, Santarmaki V, Aindelis G, Tompoulidou E, Lamprianidou EE, Saxami G, Ypsilantis P, Lampri ES, Simopoulos C, Kotsianidis I, Galanis A, Kourkoutas Y, Dimitrellou D, Chlichlia K. Lactobacillus casei exerts antiproliferative effects accompanied by apoptotic cell death and up-regulation of TRAIL in colon carcinoma cells. PLoS One; 11: e0147960: (2016).
7. Sidira M, Galanis A, Ypsilantis P, Karapetsas A, Progaki Z, Simopoulos C, Kourkoutas Y. Effect of probiotic-fermented milk administration on gastrointestinal survival of Lactobacillus casei ATCC 393 and modulation of intestinal microbial flora. Journal of Molecular Microbiology and Biotechnology, 19(4): 224-230: (2010).

8. Dimitrellou D, Kandylis P, Sidira M, Koutinas A. A, Kourkoutas Y. Free and immobilized Lactobacillus casei ATCC 393 on whey protein as starter cultures for probiotic Fetatype cheese production. Journal of Dairy Science; 97(8): 4675-4685: (2014b).

9. Sidira M, Kandylis P, Kanellaki M, Kourkoutas Y. Effect of curing salts and probiotic cultures on the evolution of flavor compounds in dryfermented sausages during ripening. Food Chemistry; 201: 334-338: (2016).

10. Dimitrellou D, Kandylis P, Petrovic, Dimitrijevic-Brankovic S, Levic S, Nedovic V, Kourkoutas, Y. Survival of spray dried microencapsulated Lactobacillus casei ATCC 393 in simulated gastrointestinal conditions and fermented milk. LWT-Food Science and Technology; 71: 169-174: (2016a).

11. Dimitrellou D, Kandylis P, Kourkoutas Y. Physicochemical and microbiological characteristics of probiotic yogurts produced with immobilized cells. Journal of Biotechnology; 185: S79: (2014a).

12. Sidira M, Saxami G, Dimitrellou D, Santarmaki V, Galanis A, Kourkoutas, Y. Monitoring survival of Lactobacillus casei ATCC 393 in probiotic yogurts using an efficient molecular tool. Journal of Dairy Science; 96(5): 3369- 
3377: (2013).

13. Quigley M. E, Hudson G. J, Englyst H. N. Determination of resistant shortchain carbohydrates (non-digestible oligosaccharides) using gas-liquid chromatography. Food Chemistry; 65(3): 381-390: (1999).

14. Gibson G. R, Roberfroid M. B. Dietary modulation of the human colonic microbiota: introducing the concept of prebiotics. Journal of Nutrition; 125: 1401-1412: (1995).

15. Al-Sheraji S. H, Ismail A, Manap M.Y, Mustafa S, Yusof R. M, Hassan F. A. Prebiotics as functional foods: A review. Journal of Functional Foods; 5(4): 1542-1553: (2013).

16. Kunová G, Rada V, Lisova I, Roèková S, VIková E. In vitro fermentability of prebiotic oligosaccharides by lactobacilli. Czech Journal of Food Sciences; 29(1): S49-S54: (2011).

17. Pacifici S, Song J, Zhang C. K, Tako E. Evaluating the effect of plant origin prebiotics (Raffinose and Stachyose) on iron status, intestinal functionality and intestinal bacterial populations in vivo. The FASEB Journal; 30(1 Supplement): 692-17: (2016).

18. Martinez-Villaluenga C, Frías J, Gómez R, Vidal-Valverde $\mathrm{C}$. Influence of addition of raffinose family oligosaccharides on probiotic survival in fermented milk during refrigerated storage. International Dairy Journal; 16(7): 768-774: (2006).

19. Martínez-Villaluenga C, Gómez R. Characterization of bifidobacteria as starters in fermented milk containing raffinose family of oligosaccharides from lupin as prebiotic. International Dairy Journal; 17(2): 116-122: (2007).

20. Martinez-Villaluenga C, Frías J, VidalValverde C, Gómez R. Raffinose family of oligosaccharides from lupin seeds as prebiotics: application in dairy products. Journal of Food Protection; 68(6): 1246-1252: (2005).
21. Dinoto A, Suksomcheep A, Ishizuka S, Kimura H, Hanada S, Kamagata Y, Asano K, Tomita F, Yokota A. Modulation of rat cecal microbiota by administration of raffinose and encapsulated Bifidobacterium breve. Applied and Environmental Microbiology; 72(1): 784792: (2006).

23. Kim S. J, Cho S. Y, Kim S. H, Song O. J, Shin I. S, Cha D. S, Park H. J. Effect of microencapsulation on viability and other characteristics in Lactobacillus acidophilus ATCC 43121. LWT-Food Science and Technology; 41(3): 493-500: (2008).

24. Dimitrellou D, Kandylis P, Kourkoutas Y. Effect of cooling rate, freeze-drying, and storage on survival of free and immobilized Lactobacillus casei ATCC 393. LWT-Food Science and Technology; 69: 468-473: (2016).

25. Xu M, Gagné-Bourque F, Dumont M. J, Jabaji S. Encapsulation of Lactobacillus casei ATCC 393 cells and evaluation of their survival after freeze-drying, storage and under gastrointestinal conditions. Journal of Food Engineering; 168: 52-59: (2016).

26. Lee W. J, Lucey J. A. Formation and physical properties of yogurt.Asian-Australasian Journal of Animal Sciences; 23(9): 11271136: (2010).

27. Amatayakul T, Sherkat F, Shah N. P. Syneresis in set yogurt as affected by EPS starter cultures and levels of solids. International Journal of Dairy Technology, 59(3): 216-221: (2006).

28. Lucey J. A, Munro P. A, Singh H. Whey separation in acid skim milk gels made with glucono- $\alpha$-lactone: Effects of heat treatment and gelation temperature. Journal of Texture Studies; 29(4): 413-426: (1998).

29. Wongputtisin P, Ramaraj R, Unpaprom Y, Kawaree R, Pongtrakul N. Raffinose family oligosaccharides in seed of Glycine max cv. Chiang Mai60 and potential source of prebiotic substances. International Journal of Food Science \& Technology, 50(8): 17501756: (2015). 